\title{
Bagua y el Perú: extractivismo, dominación patriarcal y comunalidad
}

\author{
Carolina ORTIZ FERNÁNDEZ
}

\begin{abstract}
RESUMEN
Reflexionar en torno a los códigos, las relaciones sociales y afectivas que emergen de la enunciación discursiva y los actos de las y los actores sociales que participaron en el conflicto socioambiental ocurrido en Bagua el 5 de junio de 2009, en diálogo con la teoría social clásica y la teoría de la colonialidad del poder, en primer lugar nos permite comprender otra visión del mundo y de la vida desde la perspectiva de ser "indígena"y habitante de la Amazonía en Perú; en segundo, que todo el proceso previo forma parte de las estrategias de recolonización de los territorios de nuestra América, en particular de la Amazonía y al mismo tiempo constituye un punto de inflexión, de cuestionamiento al modelo de desarrollo impuesto. A diferencia de la concentración autoritaria de poder que irradia del gobierno y del "Estado Nación", las comunidades dan lecciones de una democracia de mayor intensidad y revelan las contradicciones entre la existencia social comunitaria y el "estado nación" que representa a las corporaciones y al patrón global de poder.
\end{abstract}

PALABRAS ClAVE: Bagua, extractivismo, patriarcado, conflicto indígena, naturaleza, capital y trabajo, teoría clásica, teorías latinoamericanas.

Bagua and Peru:

Extractivism, patriarchal domination and communality

\section{ABSTRACT}

Ponder over the codes, social and emotional relationship that emerge from the discursive enunciation and acts of the and social actors involved in the socio-environmental conflict occurred in Bagua on June 5,2009 , regarding with classical social theory and the theory of the coloniality of power, on one hand, let us understand other gaze of the society and life from the perspective of being "indigenous" and inhabitant at the Amazon in Peru; on the other hand, part of the strategies of re-colonization of the territories of our America, particularly the Amazon, and constitutes a milestone about the model of development imposed. Unlike the authoritarian concentration of power from the government and the "nation state", communities depicts an intense democracy and reveal the contradictions between community social existence and the "nation state" depicted by the corporations and the overall pattern of power.

KEYWORDS: Bagua, extractivism, patriarchy, indigenous struggle, nature, capital, work, classical theory, coloniality of power 


\section{Introducción}

$\mathrm{L}$

a explotación del oro blanco, como se llamó al caucho, durante las primeras décadas del siglo $X X$, sumió a la población de los territorios amazónicos en cruentos trabajos forzados y relaciones sociales de esclavitud que permitió incrementar la acumulación Europea, sobre todo a Inglaterra mediante la apropiación de los bienes comunes y de la fuerza de trabajo de los cuerpos y territorios colonizados. En los últimos años, una vorágine de nuevos colonos nacionales y extranjeros en nombre del desarrollo y el progreso incursiona contra la Amazonía y los pueblos que la habitan ancestralmente. En junio del 2009, el expresidente Alan García, luego de los dolorosos sucesos ocurridos en Bagua, sostuvo ante cámaras: "estas personas no son ciudadanos de primera clase, que puedan decir 400.000 nativos a 28 millones de peruanos: 'tú no tienes derecho de venir por aquí, de ninguna manera, eso es un error gravísimo y quien piense de esa manera quiere llevarnos a la irracionalidad y al retroceso primitivo"1.

Permanece el viejo debate de civilización y barbarie inaugurado por Juan Ginés de Sepúlveda en el siglo XVII, continuado a lo largo de la historia colonial y republicana e incluso en el Informe Final de la Comisión especial conformada por Pilar Mazzetti, Jesús Manecés, Susana Pinilla, Ricardo Álvarez Lobo, que se encargó de investigar y analizar los sucesos de Bagua, presentada en diciembre 2009. El informe precisa que lo que faltó al gobierno fue establecer mayor comunicación con la población indígena a fin de mantenerla informada de los decretos legislativos emitidos por el poder ejecutivo, que los activistas y dirigentes de los partidos políticos, entre ellos el de Ollanta Humala, habrían exacerbado los ánimos de los indígenas. Los responsables de lo ocurrido el 5 de junio serían todos.

El comisionado Jesús Manacés sostiene que no tuvo oportunidad de leer el informe final sino tardíamente. Por eso, junto a Carmen Gómez Calleja, adjuntaron una carta y luego un informe en minoría suscrito por los dos comisionados; en él expresan su desacuerdo con el Informe Final referente a que en la Estación № 6 los manifestantes desconocieron "los acuerdos de convivencia pacífica", en tanto soslaya que para la población el operativo llevado a cabo por la policía en la Curva del Diablo, fue lo que rompió y desafió la convivencia pacífica. En el informe en minoría se sostiene que los líderes hicieron los mayores esfuerzos por mantener un canal de diálogo con los funcionarios de Petroperú y el mismo 5 de junio, representantes de los pueblos Awajún y Wampis y el Comité Local de Lucha trataron por todos los medios de evitar toda acción violenta. Manacés y Calleja responsabilizan a los que

1 Declaración de Alan García a UNIVISION y TVE el 9 de junio de 2009. https://www.youtube.com/watch?v=rlj6 XBa7pAE\&ebc=ANyPxKrj3L9B7E-jcw9Hcul2jV4dUtBIcxcnUVIW5ss9EQfRerZSuEvv3TtBBy9CfeDFMuZuP7ql

\section{2/ REVISTA DESSCIOLOGGíA 26}


dieron la orden del operativo y a los ministros del Interior y de Defensa. En Bagua Grande y Bagua capital no se garantizó la seguridad y la protección se produjo contra los manifestantes indígenas con los que la población había confraternizando. Es decir, se trató de dividirlos, fue la muerte de indígenas sin armas por disparo de balas lo que generó desconcierto y reacciones inesperadas. Finalmente, precisan que el mayor problema es que el Estado no cuenta con mecanismos institucionales para comprender las diferencias y construir políticas públicas de manera dialogante y en segundo, que no respeta los acuerdos internacionales que ha suscrito.

En el informe de la "Comisión investigadora sobre los hechos acontecidos en la ciudad de Bagua, aledaños y otros", suscrito y presentado el 2010 por el congresista Guido Lombardi Elías, se afirma que la población indígena, sobre todo la amazónica en el Perú, no ha sido integrada al espacio legal y político del estado peruano y que debido a la falta de comunicación su cultura no ha sido conocida. Lo ocurrido en Bagua sería una trágica demostración del olvido y marginación en la que se encuentra y que esto se acentuó cuando conocieron los artículos de García publicados con el título de "El perro del hortelano".

Entendiendo que la crisis que vive el planeta no sólo es económica y financiera sino una crisis de sentido, alimentaria, de cuidados, de género, epistémica, de autoridad, crisis política y sobre todo una crisis ambiental que pone en riesgo la vida del planeta, una crisis del patrón de poder moderno colonial global eurocentrado cuyo último modelo económico desde Ronald Reagan y Margaret Thatcher se impuso en el globo promoviendo el consumismo, la sobreexplotación de la Naturaleza, el extractivismo, la flexibilización del trabajo, el desempleo, el recorte de los derechos laborales, sociales y políticos; en el presente trabajo se explora el conflicto socioambiental ocurrido en Bagua, a partir de las perspectivas de las y los actores sociales que participaron en el conflicto, en diálogo con los clásicos de la teoría social y las perspectivas teóricas latinoamericanas contemporáneas.

Recoger y exponer los puntos de vista de las personas y grupos sociales en conflicto, sobre todo de los subalternizados que intervinieron en estos sucesos no solo es un instrumento metodológico, es una manera de dialogar en las dimensiones de lo público, reconociendo su validez política y epistémica e interpelando a la democracia representativa y al "Estado-nación" que niega su condición ciudadana. Constituye un cuestionamiento a lo que Hanna Arendt llamó la prepolítica como ejercicio autoritario de la dominación patriarcal en la economía, la política y el saber, que coloniza los cuerpos y territorios hasta convertirlos en supérfluos. Dialogar con lo invisibilizado y silenciado permite develar e interpelar la colonialidad del saber.

Con este fin, se exponen los acontecimientos previos a lo ocurrido el 5 de junio de 2009, en diálogo con las actoras y los actores sociales a partir de entrevistas y 
material audiovisual. Se explora la interconexión entre las políticas extractivistas, la dominación patriarcal, la colonialidad global del poder y la resistencia no sin conflictos de la comunalidad en Bagua.

Como sabemos la formación de los profesionales y técnicos que gobiernan tienen una formación académica en la que la ciencia económica y las ciencias sociales, desde la perspectiva estructural funcionalista y el marxismo eurocéntrico, con algunas variantes contemporáneas, se han encargado de legitimar las políticas de desarrollo, hoy extractivismo, impartiendo cursos de demografía y desarrollo, sociología del desarrollo, economía del desarrollo, como parte de un saber poder global eurocentrado que ocasiona el despojo y la destrucción de la Naturaleza.

Las estrategias de desarrollo extractivistas constituyen la base de formación de los políticos y los técnicos que gobiernan. Estas se expresan desde Bacon en la cosmovisión de la ciencia y tecnología de la tradición eurocéntrica, que promueve la explotación sin fin de la Naturaleza, poniendo en riesgo la vida del planeta.

Por eso, el marco teórico se irá construyendo en diálogo, en primer lugar, con las perspectivas de las actoras y los actores; en segundo lugar, de manera crítica con la teoría social clásica (Marx, Weber, Luxemburgo) y la teoría de la colonialidad del poder emergente en América Latina. Entendiendo a cada enunciado emitido como un acto comunicativo. La perspectiva dialógica vincula los rasgos externos de cada enunciado con los organizadores espacio temporales, los cuales permiten abrir vías para construir y reconstruir los enunciados desde su interior relacionándolos con la sociedad y la cultura entendidos como campos de poder, el plano individual con el plano colectivo, la micro con lo macro social. El enfoque es cualitativo desde las experiencias de las y los actores involucrados. La población está conformada por los representantes de las comunidades afectadas, los representantes del gobierno y de la sociedad. Se ha trabajado con fuentes primarias y bibliográficas.

\section{Los acontecimientos previos}

El 7 de junio de 1989, ante los diversos movimientos indígenas en el mundo, sobre todo en América Latina, cercanos a la conmemoración del quinto centenario del violento encuentro en 1992, se creó el convenio 169 de la Organización Internacional del Trabajo (OIT), ratificado por el Perú en 1994 con la Ley 26253. El convenio establece la necesidad de garantizar la autonomía interna de los pueblos y nacionalidades indígenas, el respeto de sus estilos de vida, instituciones, cultura, la consulta y participación efectiva de estos pueblos en la toma de decisiones. En el artículo dos se afirma:

\section{4/ REVISTA De SOCLLLoGíA 26}


Los gobiernos deberán asumir la responsabilidad de desarrollar con la participación de los pueblos interesados, una acción coordinada y sistemática con miras a proteger los derechos de esos pueblos y a garantizar el respeto de su integridad. Esta acción deberá incluir medidas:

a) que aseguren a los miembros de dichos pueblos gozar, en pie de igualdad, de los derechos y oportunidades que la legislación nacional otorga a los demás miembros de la población;

b) que promuevan la plena efectividad de los derechos sociales, económicos y culturales de esos pueblos, respetando su identidad social y cultural, sus costumbres y tradiciones, y sus instituciones. ${ }^{2}$

El artículo seis precisa: "Al aplicar las disposiciones del presente convenio, los gobiernos deberán (a) consultar a los pueblos interesados mediante procedimientos apropiados a través de sus instituciones representativas, cada vez que se prevean medidas legislativas o administrativas susceptibles de afectarles directamente".

A pesar que el Perú ratificó esta ley en 1994, ni desde entonces ni a lo largo de la historia, los pueblos y nacionalidades indígenas han merecido una debida y respetuosa consulta. La Ley de Consulta Previa, como veremos, ha venido siendo recortada. Si —en teoría - se pide algún parecer como ha ocurrido hace poco en el caso de las Bambas, en la práctica, se exige acatamiento, obediencia, de lo contrario se les acusa de vándalos, terroristas y delincuentes.

\section{Notas sobre el proceso de recortamiento de la ley de consulta previa}

El 17 de julio de 1995 se promulgó la Ley 26505, denominada la ley de tierras, "Ley de la inversión privada en el desarrollo de las actividades económicas en las tierras del territorio nacional y de las comunidades campesinas y nativas", como parte del proceso de liberalización del mercado de tierras en el país, ocasionando conflictos por el racismo jurídico y económico evidentes. Por ejemplo, la tecnocracia desconoce o poco le interesa que la tierra, o mejor el territorio no sea igual a mercancía para todas las peruanas y todos los peruanos. Con el objeto de facilitar la inversión privada, el artículo 11 de la ley indicada que de cierto modo permitía a la comunidad participar en la toma de decisiones: "Para disponer gravar, arrendar o ejercer cualquier otro acto sobre las tierras comunales de la sierra o selva se requerirá del acuerdo de la Asamblea General con el voto conforme de no menos

2 OIT. Oficina Regional para América Latina y el Caribe. "Convenio N 169 sobre pueblos indígenas y tribales en países independientes". 2a.ed. Lima, OIT,Oficina Regional paraAmérica Latina y el Caribe, 2007. 106p. http:// www.oit.org.pe/WDMS/bib/publ/libros/convenio_169_07.pdf 
de $2 / 3$ de todos los miembros de la comunidad"3, fue constreñido aún más, como veremos, durante el gobierno de García.

El 4 de julio de 1997 se publicó la Ley de Áreas Naturales Protegidas, según la cual estas áreas constituyen patrimonio de la nación por lo que se requiere asegurar su natural proceso ecológico manteniendo adecuadamente las cuencas hidrográficas a fin de asegurar la calidad del agua. Curiosamente, una buena parte de estas áreas desde los 80 y los 90 se encuentran continuamente amenazadas por el narcotráfico y la concesión de tierras a empresas que explotan hidrocarburos. Sierra del Divisor, por ejemplo, estuvo a punto de ser concesionado. Felizmente, en noviembre del 2015, ante la demanda de los pueblos amazónicos con la solidaridad internacional se logró que sea considerado parque nacional. Pero ¿cómo se eligen las áreas naturales protegidas y cuál es el impacto de éstas sobre las comunidades? El 13 de octubre de 2005 se emitió la Ley General del Ambiente № 28611 que estableció los principios y normas referentes a la protección y al derecho a un ambiente saludable que garantice el desarrollo sostenible del país ${ }^{4}$. Vale preguntar ¿Se cumple?

Durante el gobierno de Alan García los recortes fueron mayores. El 28 de diciembre del 2006 el ejecutivo promovió el proyecto de Ley 840/2006-PE ${ }^{5}$ mediante el cual se cambió el régimen de tierras forestales sin bosques o eriaza por una ley que incentivaba la inversión privada en actividades de reforestación. Este proyecto no fue aceptado por la Organización Regional de los Pueblos Indígenas de la Amazonía Norte (ORPIAN), la Organización Regional de AIDESEP ${ }^{6}$ y la Federación Nativa del Río Madre de Dios y afluentes, porque consideraron que la Ley en el fondo promovía la deforestación privada, debilitaba la propiedad comunal e incentivaba la venta de tierras. Hoy reconfirmamos que la reforestación con monocultivos, por ejemplo, de palma aceitera en territorios de gran diversidad produce la destrucción del ecosistema afectando la vida de las comunidades de la Amazonía. La Ley en el fondo alienta la deforestación de bosques naturales para ser reforestados con bosques artificiales, incentivado por la demanda de palma aceitera de las grandes corporaciones agroindustriales.

En diciembre del 2007, el expresidente García pidió al Congreso se le otorgue facultades extraordinarias para emitir decretos legislativos favorables al Tratado de Libre Comercio con los Estados Unidos, no importaba que estos vulnerasen la Ley de Consulta Previa, la Ley era considerada un engorro que impedía efectuar tratados de libre comercio con diferentes países.

Ley de inversión privada ... (ley de tierras) http://www.cepes.org.pe/legisla/ley26505.htm

Ley general de ambiente 28611, http://www.minam.gob.pe/wp-content/uploads/2013/06/ley-general-delambiente.pdf

5 CEPES, Revista Agraria No 85. http://www.cepes.org.pe/revista/r-agra85/LRA85-04-05.pdf

6 La Asociación Interétnica de Desarrollo de la Selva Peruana -AIDESEP- fue fundada en mayo de 1985.

\section{6/ REVISTA De SOCIOLOGGía 26}


Con las facultades obtenidas, el 20 de mayo de 2008 el Decreto Ley 1015 anuló el artículo 11 de la Ley 26505, que señala: “Para disponer gravar, arrendar o ejercer cualquier otro acto sobre las tierras comunales de la sierra o selva se requerirá del acuerdo de la Asamblea General con el voto conforme de no menos de 2/3 de todos los miembros de la comunidad". En su lugar, el nuevo dispositivo establece que para enajenar las tierras se requiere solo el $50 \%$ de los participantes en la asamblea y no los $2 / 3$ del padrón comunal, de esta manera se facilita la enajenación de las tierras comunitarias y se recorta la participación de la comunidad. La Defensoría del Pueblo, en mayo de 2008, presentó una acción contra el decreto 1015 porque no respeta el acuerdo de limitarse a la promoción del Tratado de Libre Comercio entre Perú y los Estados Unidos. El 28 de junio de 2008 se promulgó la Ley de la Selva №1090 que promueve las concesiones a empresarios por plazos renovables de 40 años, está norma prescinde de la consulta a los pueblos, niega el respeto a su integridad territorial y en la práctica promueve la venta del territorio. Por otro lado, la Facultad de Ciencias Forestales de la Universidad Nacional Agraria La Molina publicó un pronunciamiento el 04 de julio de 2008 en el que expresa su preocupación por la promulgación de la Ley 1090, Ley Forestal y de Fauna Silvestre, sin la participación consensuada de las distintas instituciones públicas y privadas del sector forestal:"Consideramos que en el texto del DL № 1090 existen graves errores conceptuales que podrían generar interpretaciones inadecuadas y contradicciones en su aplicación poniendo en riesgo el objetivo de lograr el uso sostenible de los recursos forestales y de fauna silvestre del país ${ }^{7}$.

El 9 de agosto del 2008 se inició la movilización de los pueblos de la Amazonía, exigieron la derogación de los decretos legislativos 1015 y 1073. Alberto Pizango Chota, Apu de AIDESEP anunció la movilización. En Puerto Maldonado fueron apresados 20 hermanos amazónicos, se les responsabilizó del incendio ocurrido en el gobierno regional.

La tecnocracia de los gobiernos de Fujimori y García, una burocracia supuestamente impersonal, legisló a favor de los intereses económicos de las corporaciones teñidos intensamente de racismo como expresión de la dominación patriarcal y patrimonial. Recordemos que para Weber, un clásico de la teoría social, la dominación patriarcal tradicional no desaparece plenamente sino que subyace en la dominación patrimonial y en la racionalidad burocrática. La dominación patriarcal y patrimonial está asociada a quiénes y cómo ser ejercen la relaciones y estructuras históricas de autoridad, supone centralidad y concentración de poder, exige la obediencia al jefe / autoridad, legitimado por la norma, que se arroga la representación de los subalternizados.

7 Boletiín Informativo Caoba N³ - 2008, Universidad Nacional Agraria La Molina. http://www.lamolina.edu.pe/ proyectocaoba/Boletin\%203.pdf 


\section{Movilización comunitaria en Bagua}

La desconfianza fue creciendo por los continuos ofrecimientos de diálogo incumplido. El 18 de agosto del 2008, según DS № 058-2008-PCM se declaró el estado de emergencia en Bagua y Utcubamba en el departamento de Amazonas y Loreto; y en Echarate, en la Convención, Cusco. La movilización comunitaria indígena fue contundente, logró que el 22 de septiembre del 2008 el congreso derogara los decretos legislativos 1015 y 1073 y ofrecieron revisar la Ley 1090, Ley de la Selva. El acuerdo fue suscrito por el presidente del Congreso Javier Velásquez Quesquén y los representantes de los Pueblos Indígenas Amazónicos, el gobierno ofreció incorporar el proceso de consulta previa promovido en el convenio 169 de la Organización Internacional de Trabajo.

El 12 de marzo del 2009, ante la promesa incumplida de revisar la Ley 1090, AIDESEP solicitó al Congreso y al presidente del Consejo de Ministros se constituya una mesa de diálogo. Pidieron la derogatoria del decreto legislativo, y en su lugar elaborar juntos una nueva norma que sea beneficiosa no sólo para los pueblos amazónicos, sino también para los pueblos andinos y costeños. Enviaron su pedido al Congreso, pero tampoco fueron atendidos. El 9 de abril iniciaron una huelga general indefinida. El 16 del mismo mes, las comunidades asháninkas con arcos y flechas, con la solidaridad del pueblo de Bagua y la organización comunitaria popular de los barrios y las organizaciones sociales tomaron el aeropuerto Atalaya de Ucayali. ${ }^{8}$ El 20 de abril, el primer ministro Yehude Simon se reunió con los dirigentes de AIDESEP y acordaron formar una comisión multisectorial, pero todo continuó igual.

El 5 de junio de 2009, irónicamente el "día del medioambiente", entre el inconmensurable verdor, las balas y las bombas lacrimógenas dispararon por la espalda. El pueblo amazónico se sintió traicionado, los resultados fueron sumamente dolorosos, más de 150 heridos, 32 muertos, entre ellos 23 policías. El mayor, PNP Felipe Bazán, comandó el desalojo de la población en la curva del diablo. El Apu Santiago Manuin salió con las manos en alto en señal de paz, recibió como respuesta una ráfaga de balas, le destrozaron los intestinos. El fiscal pidió la cadena perpetua para ély 35 años para 53 hermanos indígenas.

\section{Bagua}

El pueblo aguaruna (en quechua) y awajún en (lengua awajún) habita en los departamentos de Amazonas, San Martín, Cajamarca y Loreto. Según el INEI, la población Aguaruna y Huambisa, está constituida aproximadamente por 42588 habitantes, de

8 Como fue posible corroborar a través de las conversaciones que sostuvimos con la población de Bagua, en agosto del 2016, agradezco el apoyo de Adolfo Quiroz.

\section{8/ REVISTA DESOCIOLOGǴA 26}


los cuales el $12 \%$ de la población vive en el departamento de Amazonas: el 20\% en la provincia de Bagua y $75 \%$ en Condorcanqui.

CUADRO 1: POBLACIÓN

\begin{tabular}{|c|c|c|c|}
\hline $\begin{array}{c}\text { Departamento } \\
\text { Provincial / Distrito }\end{array}$ & $\begin{array}{c}\text { Población } \\
\text { total }\end{array}$ & $\begin{array}{c}\text { Población } \\
\text { indígena }\end{array}$ & $\begin{array}{c}\text { Porcentaje de } \\
\text { población indígena }\end{array}$ \\
\hline Amazonas & 354171 & 42588 & 12.0 \\
Bagua & 74568 & 15279 & 20.5 \\
Aramango & 13869 & 826 & 6.0 \\
Imaza & 21911 & 14451 & 66.0 \\
Condorcanqui & 36037 & 27309 & 75.8 \\
Nieva & 17104 & 12917 & 75.5 \\
El Cenepa & 9568 & 6803 & 71.1 \\
Río Santiago & 9365 & 7589 & 81.0 \\
\hline
\end{tabular}

Fuente: INEI. Censos Nacionales de 1993.

La provincia de Bagua está ubicada en el departamento de Amazonas y consta de seis distritos: Bagua, La Peca, Aramango, Ymasa, Copallín y El Parco. La historia/ memoria oral, escuchada y recogida durante el recorrido por la zona, comenta que este pueblo y en general, los pueblos de la Amazonía resistieron la colonización española. El historiador Waldemar Espinoza Soriano señala que fueron obstáculos geográficos y climáticos los que impidieron la colonización ${ }^{9}$. Fueron los franciscanos por el sur y los jesuitas por el norte los que ingresaron, a decir de Espinoza, al inhóspito territorio.

Según Alfredo Torero, la palabra Bagua proviene de la lengua ancestral del mismo nombre del Nororiente peruano (Torero, 1993), el saber popular nos indica que deviene de agua. Ruth Shady, precisa que los habitantes de la cultura Bagua se dedicaron históricamente a la agricultura, la pesca, la ganadería y la alfarería (Shady, 1973). Hoy sabemos que fueron expertos en arte textil y que continúan siéndolo. En la actualidad, un $42 \%$ se dedica a actividades primarias no remuneradas como la agricultura y la pesca, cultivan sobretodo yuca y plátano.

Por temporadas, los jóvenes trabajan fuera de sus comunidades en empresas o cooperativas cafetaleras y arroceras o en pequeñas unidades de comercio ambulatorio, en los mercados, restaurantes y bares de la ciudad. Las mujeres suelen trabajar en los restaurantes. El pequeño comerciante les provee de habitación, comida y bajísimo salario. Se articulan relaciones comunitarias con relaciones de servidumbre, mercantiles y salariales. En nuestro recorrido por la ciudad, se pudo apreciar que los citadinos les tienen gran aprecio y se solidarizan con ellos. El 10\% de los entrevistados,

9 Amazonía del Perú, Historia de la Gobernación y la Comandancia General de Maynas. Lima, Banco Central de Reserva del Perú, 2007. 


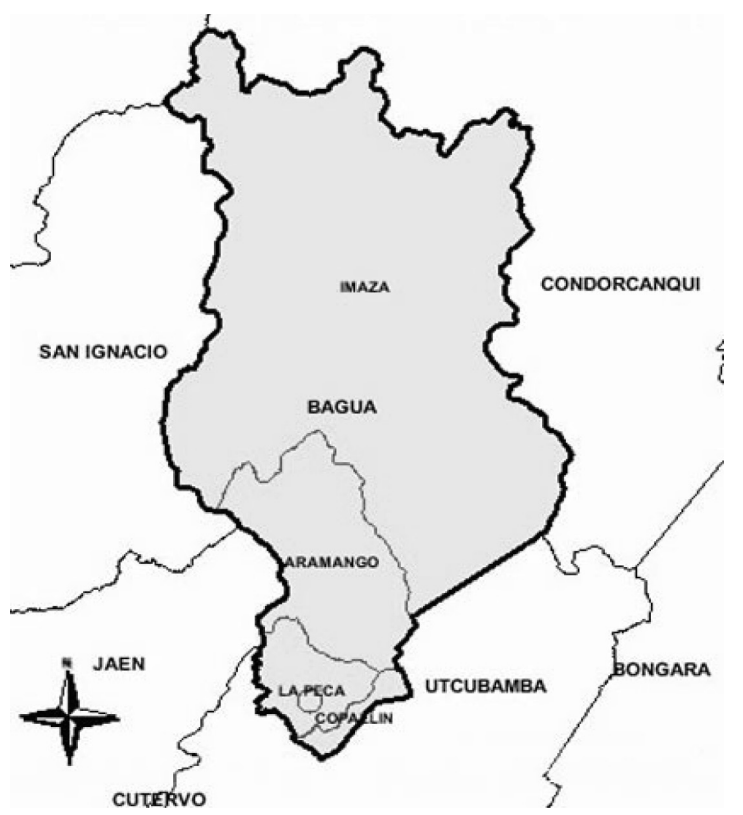

los calificó de violentos, sucios, enemigos del progreso, el $90 \%$ los identificó como pacíficos jóvenes y pueblos olvidados que requieren urgente apoyo.

El awajún pertenece a la familia lingüística jíbara. La gran mayoría de jóvenes es bilingüe, se comunican en su lengua materna y en español, algunos han realizado estudios superiores. La preeminencia de la cultura occidental y del eurocentrismo a través de los medios de comunicación y las instituciones educativas hegemónicas entran en conflicto con su visión del mundo y de la vida, con todo más del $60 \%$ se reafirma en diálogo con la cultura occidental y un $35 \%$ se pierde ella. Corroboramos, que si bien poseen una afirmativa identidad étnica como lo afirma Reagan, la destrucción de sus territorios los despoja del lugar que permite la comunión del cuerpo y de la mente. Una de sus primeras organizaciones autónomas fue el Consejo Aguaruna Huambisa, fundada en 1970.

\section{Las actoras y los actores sociales y políticos}

a) Los representantes del gobierno. Las perspectivas desarrollistas y extractivistas

Al finalizar la Segunda guerra mundial, la reestructuración de la economía mundo moderno y la colonialidad global del saber y del poder generaron las condiciones de posibilidad de las perspectivas desarrollistas basadas en la idea de progreso lineal, 
que reclasificó a las sociedades en "desarrolladas" y "subdesarrolladas", los países subdesarrollados como los de América del Sur debían propiciar políticas de desarrollo teniendo como modelo al denominado Primer Mundo.

En las últimas décadas, las políticas globales de desarrollo propiciadas por lo que Aníbal Quijano denomina bloque imperial de poder y Anthony Guiddens, gobierno mundial invisible, formado por las corporaciones, el grupo de los ocho, las instituciones financieras y de violencia tales como el Banco Mundial, FMI, BID, OTAN, tejen redes con las instituciones y grupos de poder, nacionales y regionales a nivel económico, educativo y cultural e imponen medidas que repercuten en la vida económica, en la cotidianidad de las gentes y en el saber; además de economistas, abogados, ingenieros o administradores de negocios, profesionales de las ciencias sociales avalan la promulgación de leyes y la ejecución de los proyectos de "desarrollo" que se imponen y afectan a los pueblos de la Amazonía y al territorio, beneficiando a las corporaciones. Los pueblos y nacionalidades indígenas de la Amazonía son considerados primitivos, menores de edad, atrasados, tradicionalistas.

Los representantes del gobierno que participaron de manera directa en el conflicto, entre ellos, el expresidente Alan García, la exministra de Comercio Exterior Mercedes Araos, la ministra del Interior Mercedes Cabanillas, la ministra de Justicia Rosario Fernández, el general Vidaurre, el primer ministro Yehude Simon, el congresista Hildebrando Tapia, entre otros; son profesionales de la tecnocracia estatal y privada que trabajan para despojarlos de ése atraso obligándoles a "integrarse" al mercado y a la globalización, si se oponen o no "obedecen", son "delincuentes", como los llamó Mercedes Cabanillas ${ }^{10}$, exministra del interior; "son perros del hortelano" o "ciudadanos de segunda categoría", como calificó García a la población de Bagua que el 2009 se movilizó en defensa de su territorio y de la vida. García responsabilizó de los hechos al gobierno de Venezuela: "Esto sólo le interesa a potencias petroleras extranjeras (...) ¿A quién le conviene que el Perú se detenga? A los competidores del Perú"11. Por su parte, el congresista Hildebrando Tapia afirmó: "El estado tiene el deber de defenderse y defender el sistema". La ministra de Justicia, Rosario Fernández ${ }^{12}$, responsabilizó de las muertes a Alberto Pizango, presidente de la Asociación Interétnica de Desarrollo de la Selva (AIDESEP), y exigió su presencia ante la justicia. La violencia y las muertes habrían sido promovidas por los discursos violentistas del líder.

10 "Pizango es un delincuente", declaró Cabanillas al referirse a uno de los líderes de AIDESEP.

11 Declaración de Alan García a UNIVISION y TVE el 9 de junio de 2009. https://www.youtube.com/watch?v=rlj6 XBa7pAE\&ebc=ANyPxKrj3L9B7E-jcw9Hcul2jV4dUtBIcxcnUVIW5ss9EQfRerZSuEvv3TtBBy9CfeDFMuZuP7ql

12 Declaraciones de la ministra Rosario Fernández a Enlace Nacional, el domingo 07 de junio, a 11:45 a.m. http:// enlacenacional.com/2009/06/05/enfrentamiento-entre-policias-y-nativos-en-bagua-deja-tragico-saldo/ 
Las palabras de García, Cabanillas, Tapia, Aráoz nos recuerdan a Ginés de Sepúlveda cuando llamó"gentes bárbaras"a los habitantes de estas tierras, que por su "condición natural deben obedecer á otros", 13 a aquellos que demuestran un espíritu superior y"varonil", pero como los habitantes de estas tierras se negaron a obedecer, les declaró "las justas causas de guerra". En este imaginario civilización equivale a Europa y "espíritu superior y varonil" a hombre.

García, sus ministras, congresistas y los grupos de poder económico y político a los que representan, al igual que Sepúlveda, en nombre de una supuesta superioridad biológica e intelectual y, en nombre del padre (el estado y el mercado), cuya autoridad proviene de aquellos que "demuestran espíritu superior y varonil" (dominación patriarcal) y, en nombre del mercado global y el "desarrollo", legitimados por el saber hegemónico, también les declararon la guerra y, una vez más, se perdieron muchas vidas.

En una entrevista que realizó César Hildebrandt $(\mathrm{CH})$ a la entonces ministra Mercedes Aráoz (MA), el periodista sostuvo que lo que estaba en juego eran modelos ambientales distintos:

CH: Lo que no se entiende es que las tribus amazónicas, las 65 etnias que están en juego, no están planteando solo la intangibilidad patrimonial de sus territorios, sino que están planteando un modelo ambientalista distinto.

MA: Mire para que...

$\mathrm{CH}$ : ¡Ese es un gran problema!

MA: Pero es que no es verdad que sea así, lo que se está buscando realmente es que se defina sus defensas territoriales eh (...) Ellos no dicen que están en contra de la inversión privada, todo lo contrario. Lo que hemos venido conversando con varios de ellos es que se tenga claridad de que la propiedad que ellos tienen sea bien definida, que se les den los títulos de propiedad y allí el mea culpa del gobierno...

CH: Sí, pero...

MA: La mea culpa es que no hemos avanzado como se debe en el reconocimiento. Se ha avanzado, no lo suficiente, todavía queda más de 300 comunidades que no han tenido ese reconocimiento territorial, no ha habido la demarcación. Se debe generar un espacio clave, pero en ningún momento se viola su intangibilidad, esa norma no está orientada a eso. Hay una orientación política y este es un juego político posterior, deróguese o no la norma, lo que querían es simplemente cambiar el modelo económico que va mucho más allá y no son las comunidades... ${ }^{14}$

13 Juan Ginés de Sepúlveda, Tratado sobre las justas causas de la guerra contra los indios, México, FCE,1996.

14 César Hildebrandt entrevista a Mercedes Araos, El perro del hortelano, https://www.youtube.com/ watch?v=t6c6nqkyyLI , subido el 15 de junio del 2009 
La ministra formada en todos los niveles educativos con la ciencia y la técnica eurocéntrica solo conoce y explica el mundo a partir del fundamentalismo neoliberal; por eso, para ella, las comunidades amazónicas estarían a favor del modelo de desarrollo neoliberal, estarían a favor de la inversión y la propiedad privada, lo que reclamarían es la falta de reconocimiento territorial en tanto carecen de títulos de propiedad. El error del gobierno habría sido no haber gestionado debidamente los títulos.

Finalmente añade, contradiciendo lo anterior, que lo que estaba de por medio era un proyecto político de las comunidades consistente en cambiar el modelo económico. Para ella, las comunidades, en tanto no tienen los valores y conocimientos que ella y los grupos de poder sostienen, carecen de la capacidad de reflexionar sobre sus vidas carecen del derecho de plantear, decidir y defender sus proyectos de vida.

Las imágenes racializadas que las ministras Araoz, Cabanillas y la periodista Rosa María Palacios tienen de las comunidades amazónicas son construidas desde la visión blanco mestiza de los sectores medios, "clases medias altas", asociadas al poder económico y político, a los medios de comunicación y al estado. Estas imágenes difunden que las comunidades amazónicas serían violentas por naturaleza; visión que divulgan a través de todos los medios escritos y audiovisuales, los nativos serían irascibles, exacerbados, no saben pensar y menos reflexionar por sí mismos; por eso, había que responderles con balas.

Veamos la conversación entre Mercedes Cabanillas (MC) acompañada del general Vidaurre, y la periodista Rosa María Palacios (RMP).

RMP: Este equipo que había enviado a la zona, había ya realizado varios operativos, tenía mucha experiencia. Tomar la carretera es un delito, hay que decirlo, no es un acto pacífico, (...) usted me ha estado diciendo que han mandado dos generales altamente capacitados, de primer nivel, ¡que pasó! (...).

MC: ¿Por qué tan exacerbados, tan violentos los nativos? Yo creo que tú lo has dicho en parte, es de la manipulación de AIDESEP y de Pizango. Les han hecho creer que ya todo está vendido y qué están sin propiedad sobre la tierra y que el agua ya está privatizada.

RMP: Esta mañana, general tal vez nos pueda usted ayudar, esta mañana se inicia el operativo policial como se ha iniciado otras veces, yo me imagino que lo primero que se hace es acercarse a la población que está allí y pedirles que por favor se retiren porque va a haber un operativo de despeje. ¿Eso se llegó a dar en este caso?

General Vidaurre: Esa alternativa ya se hizo anteriormente.

RMP: Pero el día de hoy, a las cinco de la mañana, antes que empiece el operativo, ¿hubo una conversación inicial? [...] ¿que pasó? Yo escuché a un reportero que decía: "me zumbó la bala al lado", entonces, la bala viene de la policía primero 
dicen los nativos: "nosotros hemos atacado, porque ellos nos han atacado primero a balazos" [...]

General Vidaurre: Antes ya se ha tratado, pero no hubo ningún resultado positivo $[\ldots]$

RMP: Lo que los civiles dicen es que fueron, que ustedes lo hacen muy bien, empujan a la gente, dispersan, van empujando empujando hasta que llegan a la carretera y la retiran, esto no funcionó esta vez, ${ }^{15}$ y además enterada la población que esto había pasado, se armó en Bagua un enfrentamiento con la policía [...] he estado escuchando lo que hablaba el director del hospital de Bagua, los balazos en la plaza de armas

MC: Había destrucción de establecimientos públicos, había violencia [...] la policía tiene que velar por la seguridad ciudadana...

RMP. ¿Era necesario meter bala ahí también?

MC: Yo no sé si allí se haya producido enfrentamiento [...]

General Vidaurre: Lo que ha pasado en la ciudad de Bagua Chica es que, la policía, específicamente el comisario de Bagua Chica, frente a la situación de la población que se levanta, en principio lo que hace es proteger su comisaría, las armas, la documentación. Le enviamos refuerzos [...] con unos helicópteros con la gente de Dinandro que también había viajado a la zona y a partir de ahí ha tomado un posicionamiento de la comisaría y de la plaza, los balazos que se escuchan son seguramente disparos que se hacen al aire [...].

RMP: Hablaban de un estudiante muerto que había salido a la plaza y que le había caído una bala perdida.

General Vidaurre: El fiscal ha estado ahí, seguramente que en las investigaciones se va a determinar las formas y circunstancia cómo ha muerto este estudiante... RMP: ¿Se da cuenta? Esto nunca ha pasado general, es como si la policía, así como los nativos perdieron el control, la policía perdió el control de la situación también y se le fue de las manos. ${ }^{16}$

Las fuerzas policiales, en nombre del "Estado-nación" (en nombre del padre), con el pretexto de "velar por la seguridad ciudadana", como lo afirma Mercedes Cabanillas y que para el general Vidaurre y el comisario de Bagua Chica supone ante todo (en sus palabras) "proteger su comisaría, las armas, la documentación", decidieron disparar, nada importó la vida de la población; la vida de los indígenas y la de los jóvenes no "blancos" no valen nada. Para Mercedes Cabanillas, la violencia exacerbada de los indígenas manipulados por sus líderes merecía una respuesta violenta.

El patrón moderno colonial global, que encarna el neoliberalismo difundido por las instituciones educativas, las universidades, por la ciencia económica hegemónica

15 En lugar de este procedimiento, todo indica que la policía recibió la orden de arremeter con balas.

16 Rosa María Palacios entrevista a Mercedes Cabanillas, Prensa Libre, 5/9/2009. https://www.youtube.com/ watch?v=upLUGHNB6WI

\section{4/ RELUSTA DE SOCOLOOGÍA 26}


y los medios de comunicación afianza las estrategias de violencia como expresión del racismo asociado a la dominación patriarcal que se ejerce desde el estado y sus instituciones tutelares a través de la legislación, el aparato jurídico, la política económica y al criminalizar toda protesta. Racismo, dominación patriarcal y extractivismo son interdependientes. La dominación patriarcal se expresa en la centralidad y concentración del poder en la toma de decisiones en manos del ejecutivo y el presidente amparados por la Constitución de 1993, esto a su vez se reproduce en cada instancia de poder. El orden social y las estructuras y relaciones históricas de la dominación patriarcal se organizan a partir de este principio vinculado estrechamente a los niveles jerárquicos establecidos por la acumulación incesante. El mercado aparece como una estructura libre y no como una estructura histórica tejida de relaciones de poder que exige la intervención del "estado nación" (el padre de la patria) y sus instituciones tutelares, las fuerzas policiales.

El congresista Tapia en una declaración televisiva explicó lo que Vidaurre y las fuerzas policiales callan; en nombre del Estado tienen el deber de "defender el sistema", el modelo de desarrollo, es decir, asume la defensa de las corporaciones mediante la violencia contra la "gente fiera", tal como la calificó Rosa María Palacios:

RMP: Hoy día Juan Carlos Tafur, recordaba una cosa que es cierta, esta es la zona de los Chachapoyas, los Chachapoyas son invencibles, los Incas no lograron conquistarlos, Sendero Luminoso no logró entrar allí, es gente fiera, que si no acepta las condiciones voluntariamente, no se les puede imponer, entonces, hay que llegar a una comunicación correcta con esta gente

MC: Hay un gran trabajo, no son los únicos, hay otros también que son muy aguerridos como los awajun, que están en la estación seis [...] el gran responsable es el señor Pizango.

RMP: ¿Por qué hicieron al señor Pizango interlocutor?

MC: Eso habría que analizarlo políticamente [...]

RMP: (Insiste) ¿Por que hicieron al señor Pizango interlocutor?

MC: Yo lo que creo es que tal vez no se logró contactar a los verdaderos interlocutores que habían sido los Apus [...] lo otro es que yo quiero insistir en que el gran responsable es el señor Pizango. ${ }^{17}$

Ninguno de los representantes del gobierno asumió responsabilidad alguna, todos increparon al "fiero" de Alberto Pizango por un supuesto discurso violentista y terminaron calificando de delincuentes a los representantes de los pueblos indígenas de la Amazonía.

17 Ibídem. 


\title{
b) La organización comunitaria y la representación. La defensa de una vida digna
}

Entre los representantes de las comunidades participaron Alberto Pizango, dirigente de AIDESEP, y Shampion Nomingo Cesén. El primero manifestó:

\begin{abstract}
El día de hoy a las 5 de la mañana han ordenado matar a nuestros hermanos, vía aérea con helicópteros como si fuéramos delincuentes. [...]

Los policías fueron a atacar, los pueblos indígenas no iniciaron, hasta el día de ayer, hasta las cinco de la mañana de hoy estuvo muy tranquilamente, hasta que intervino la policía [...] la causa de los pueblos indígenas es defender la vida, por ese simple hecho de defender la vida, cuando se reclama derechos con una vida digna, el gobierno responde con balas. ${ }^{18}$
\end{abstract}

AIDESEP:"Meses y meses en Lima de 8 de la mañana a 8 de la noche, que se debatirá, mañana, pasado". Nunca hubo verdadera voluntad de diálogo.

Para los representantes de las comunidades afectadas, los pueblos que representan no son delincuentes ni terroristas, son pueblos pacíficos que lo que han hecho es defenderse ante el inesperado ataque policial. Remarcan que el gobierno - por el racismo evidente - en tanto no les permiten tener una "vida digna" nunca tuvo voluntad de diálogo. Ante sus continuas demandas, revelan que pasaron meses y meses sin respuesta alguna.

Champion Nomingo Cesen, en una entrevista realizada por César Hildebrandt en el 2009, reitera mediante un yo colectivo / un nosotros, que la población tuvo que defenderse. Para él y la comunidad que representa la violencia se origina en el racismo, expresado en el "sistema político" y en la ley que defiende los interese de una elite, por eso a los representantes del gobierno no les interesa responder y menos dialogar ni consultar; demanda la urgencia de derogar la ley y elaborar otra respetando los intereses de todas las regiones:

Nosotros no hemos iniciado, es el sistema político, el racismo ha propiciado... nos hemos matado los dos, como dicen mis viejos tenemos que sentarnos para hablar. Pedimos derogar el decreto ley, normas cuestionadas y hacer un nuevo decreto que represente los intereses de los pueblos amazónicos, andinos y costeños. La comisión establecida no es un mecanismo adecuado, insistimos en la posibilidad de derogar y hacer una nueva norma. [...]

Los policías han alentado, los policías han ido con armas de fuego, nosotros no somos terroristas, nosotros hemos ayudado a pacificar. Nosotros estamos invocando al congreso que se debata... ${ }^{19}$

18 Declaración de Alberto Pizango, Canal N, 5 de junio 2009.

19 Entrevista de César Hildebrandt a Champion Nomingo Cesen, el 7 de Junio del 2009, en el "El Perro del Hortelano" de RBC, sobre los hechos de Bagua. 
Las relaciones de autoridad en la organización comunitaria reside en la soberanía de la comunidad, las decisiones son tomadas luego de un proceso de diálogo colectivo; el Apu, por sus habilidades, su experiencia y capacidad representa la autoridad, pero una autoridad desconcentrada pues tiene la responsabilidad de obedecer las decisiones de la comunidad. Por eso, Champion Nomingo Cesen, representante de AIDESEP, afirma que responsabilizar al señor Pizango es un error, pues "El señor Pizango ha obedecido las decisiones colectivas de las comunidades, el señor Pizango es un intermediario".

La organización, las relaciones de autoridad y tomas de decisión en las comunidades no están centralizadas ni concentradas en los dirigentes si no en sus representados. Las decisiones son tomadas por la comunidad en pleno:

Nosotros dependemos de las decisiones de las comunidades, los comuneros están replegados a sus comunidades y están evaluando. Por ejemplo en San Martin y otras regiones sigue la protesta, el pedido es: 1. que se instale una comisión multisectorial para ver los casos de matanzas en el Amazonas, 2. que se levante el toque de queda, tercer punto no persecución a los dirigentes, señor Hildebrandt, aquí nadie ha ordenado, si a usted le matan a sus hermanos, hijos, ríos.... ${ }^{20}$

En la organización comunitaria, la representación no tiene carácter autoritario patriarcal como suele ocurrir en las democracias representativas, en éstas los representantes se alejan del demos y deciden por si solos. En ese sentido, considero que las comunidades afectadas no sólo dan lecciones de una "democracia de mayor intensidad"21, sino que ésta tiene principios distintos a la democracia representativa, que nace de la monarquía, representa el poder económico y patriarcal del rey en la experiencia europea.

La Federación Regional de Mujeres Ashaninkas, Nomatsiguengas y Kakintes de la Selva Central (FREMANK), condenó y rechazó la agresión y la violencia, la falta real de diálogo y voluntad para resolver los cuestionamientos a numerosos decretos legislativos que afectan a los pueblos indígenas. Solicitaron que se deroguen los decretos legislativos que afectan al territorio y a los pueblos indígenas o que se suspenda su vigencia por 6 meses. Durante este tiempo los y las representantes de los pueblos indígenas y del gobierno "podrán sentarse en una mesa de diálogo para conversar y elaborar de manera conjunta una propuesta respetuosa y resarcitoria de los derechos indígenas reconocidos internacionalmente ${ }^{\prime \prime 22}$. Entre ellos el derecho a la consulta previa.

20 Ibídem, entrevista citada.

21 Democracia de mayor intensidad es un término propuesto por Boaventura de Souza Santos.

22 Pronunciamiento de la Federación Regional de Mujeres Ashaninkas, Nomatsiguengas y Kakintes de la Selva Central (FREMANK), 9 de junio de 2009. http://www.justiciaviva.org.pe/nuevos/2009/junio/11/7.pdf 


\section{El patrón moderno colonial eurocentrado y el patrón comunitario. Eurocentrismo, tiempo y naturaleza}

Alejandro Coronil nos recuerda que para los profesionales formados en ciencias sociales con la visión eurocéntrica — una mayoría—, la noción de tiempo, sobre todo la concepción del "tiempo es oro" suele prevalecer sobre el territorio y la cultura sobre la Naturaleza. Esto se difundió en todas las disciplinas, pues hasta hace pocos años, en los planes de estudio de las ciencias sociales la Naturaleza casi desapareció, quedó condenada a ser valorada sólo en términos de mercado como "recursos" o materia prima o mercancía, hoy comodities, y los seres humanos como "recursos humanos". Esta visión de las ciencias sociales ha comenzado a resquebrajarse por la interpelación de los movimientos de sociales, movimientos epistémicos y artísticos que aparecen en escena desde los años 90 , me refiero sobre todo a las reflexiones y propuestas que expresan las mujeres y los pueblos y nacionalidades indígenas.

Como lo precisa, acertadamente Amat y León, la cordillera de los andes, una de las más bellas y complejas geografías del planeta, constituye la columna vertebral del territorio. Las corrientes marinas y los fenómenos atmosféricos en los andes originan una gran variedad de climas y una gran biodiversidad en los diferentes pisos ecológicos. Esta maravillosa biodiversidad hizo posible la conformación de una gran civilización antes del siglo XV. La altura de la cordillera propició la verticalidad en la dinámica de la vida permitiendo la subsistencia de entre 10 y 20 millones de habitantes. Contribuyó a formar múltiples ecosistemas con un paisaje, cultivos y arquitectura propias, desde las altas montañas hasta el mar, por eso podemos afirmar que la naturaleza / el territorio da pautas de biosocialización que deja profundas huellas en nuestras vidas.

La relación colonial trastocó todo esta dinámica con políticas económicas y de gestión insostenible porque rompió el equilibrio logrado entre los habitantes y el territorio, ocasionado ciclos de bonanza y destrucción caracterizados por la explotación del caucho, los hidrocarburos, el oro, la deforestación, la construcción de carreteras e infraestructura sin consulta previa, poniendo en riesgo la vida de la biodiversidad y de la población. Lo que está en juego son patrones e intereses distintos en relación a la economía, la cultura, la Naturaleza, la vida en general. Para los profesionales, representantes del gobierno y el estado, formados con una visión eminentemente eurocéntrica, la Naturaleza es un objeto sin vida, se reduce a un conjunto de recursos o materias primas que requieren ser extraídos y explotados lo mejor posible. La Naturaleza ha sido y es subyugada y explotada según los requerimientos del patrón moderno colonial global.

Para los pueblos y nacionalidades indígenas la Naturaleza es un ser vital, en ella todo tiene vida, el ser humano es hijo de la Naturaleza. A los pueblos que sostienen 
esta visión y a los ambientalistas que la defienden se les califica de atrasados, enemigos del progreso y la civilización. En las diversas especies no humanas se encuentran relaciones de cooperación. Es posible que la organización comunitaria de estos pueblos haya sido aprendida a partir de la urgencia de afrontar el reto de un territorio complejo e inspirándose en la observación de las especies no humanas. Son saberes ancestrales que el patrón moderno colonial eurocentrado y la dominación patriarcal pretendió exterminar. El punto de partida de la organización autónoma comunitaria es el conocimiento del territorio, conocer el territorio implica su comprensión, respetar su propio ritmo interno; por eso, todos tienen responsabilidades frente a él y la comunidad, siendo esto crucial para la vida, aprendieron a tomar decisiones de manera colectiva.

c) Desde la sociedad, se pronunciaron: la población de Bagua, la defensoría del pueblo y algunos periodistas.

Los médicos están desesperados porque no tienen ni los medicamentos ni los instrumentos necesarios" (anunciaban algunos periodistas en los medios de comunicación). Una joven mujer aseveró: "Por culpa del gobierno se han muerto mis hermanos, se han muerto mis ríos". Otra joven madre declaró desgarradoramente en español y en su lengua materna: "Han matado a mi hijo. Felipe Fabio es mi hijo, él no llevó escopeta, nada, lo mataron, por eso estoy llorando". A su vez, uno de los miembros de la comunidad informó que Felipe llegó muerto a Chiriaco. En Imacita, otra madre en su lengua materna, el awajún, expresó:

Escúchanos por favor Alan García, tu eres el responsable porque nos estás exterminado, [...] nos estás vendiendo, tu eres terrorista, defendemos nuestro territorio de armamento, nuestra única arma de defensa sólo flechas y palos que no son de largo alcance, [...] tú nos exterminaste con el uso de armamento, balas, helicópteros y mataron a nuestros hermanos, hermanas, estudiantes, profesores, hijos. Alan te pedimos que vengas acá para que nos pagues la deuda que tienes con nosotros, Alan tú vendes nuestro pueblo, nuestro petróleo, oro, agua, contaminas nuestro medio ambiente y así nos dejas más pobres. Nosotros los Awajún-Wampis no te hemos elegido para que nos extermine si no para que nos ayudes $[\ldots]^{23}$

Ante las palabras de Alan García: ¡¡A quien no le conviene que se extraiga riqueza del subsuelo! A quien le conviene que el Perú se detenga!", un grupo de mujeres respondió:

23 Programa "Enemigos íntimos", Director: Beto Ortiz, Madre indígena reclama Alan García". Recuperado, 10 junio 2009. https://www.youtube.com/watch?v=D--_jZ6KHpw 
Nosotros no somos terroristas señor García, nosotros no queremos que mueran nuestros bosques, nuestros ríos ni humildes policías ni nuestros jóvenes hijos. Nosotros no somos terroristas, contra terroristas hemos luchado señor presidente, usté es terrorista señor García. Indígenas son pueblos olvidados.

Un joven afirmó: "A las 6.30 policías empezaron a disparar y a arrojar bombas lacrimógenas, nosotros somos pacíficos".

Un representante de la Defensoría del pueblo expresó ante cámaras:"La Defensoría hizo un análisis ratificado por la comisión de constitución. La ley no respeta la identidad cultural de lo pueblos indígenas. Yo creo que deben haber responsables, los jueces lo dirán".

La población de Bagua entrevistada, sobre todo mujeres, se expresa en su lengua materna y en español mediante un yo plural, un yo colectivo que en primer lugar se autodefine como una comunidad pacífica:"nosotros no somos terroristas", "nosotros somos pacíficos". En segundo lugar, evidencia la injusta, racista y autoritaria "integración" de la "nación peruana", porque integra exterminando, destruyendo, "nos estás exterminado, [...] nos estás vendiendo, tu eres terrorista", integra sin oír, sin comprender, porque en el país, en el nombre del padre/Estado y de las corporaciones que defiende, configurado en la concentración de poder en el presidente y el ejecutivo, y en las corporaciones avalado por la Constitución vigente, característico del orden sociosimbólico patriarcal, se impone el despojo de los bienes comunes, un único modelo de desarrollo, una sola lengua y una sola visión del mundo, una sola manera de entender la economía, la jurisprudencia, la naturaleza; se desconoce la diversidad y complejidad territorial, lingüística y cultural que resquebraja la idea de Estado nación y sus fronteras. Se cuestiona enfáticamente la concentración de poder que se expresa en García: “Alan tú vendes nuestro pueblo, nuestro petróleo, oro, agua, contaminas nuestro medio ambiente y así nos dejas más pobres". Y le exigen la rendición de cuentas: "Alan te pedimos que vengas acá para que nos pagues la deuda que tienes con nosotros". Al mismo tiempo, revela otras maneras de entender la vida, en la que todo lo existente en la Naturaleza (en tanto ser vital) vale tanto como los seres humanos que la habitan: "nosotros no queremos que muera nuestros bosques, nuestros ríos ni humildes policías ni nuestros jóvenes hijos". Por último, al señalar que los "indígenas son pueblos olvidados" explican que sienten en carne propia carencias vitales.

Entre los periodistas, podemos mencionar la solidaridad de César Hildebrandt, de Beto Ortiz y numerosos reporteros que estuvieron en la zona, entre ellos, Alonso Gamarra y el periodista del Vicariato de Jaén, Ronar Espinoza Guerrero, quien fue entrevistado vía teléfono por César Hildebrandt ${ }^{24}$, Espinoza denunció la desaparición

24 C. Hildebrandt entrevista a Ronar Espinoza en el programa El perro del hortelano,RBC televisión, 7 de junio de 2009.

\section{0 / REEUSTA DE SOCOLLOGíA 26}


de numerosas personas, la persecución de dirigentes, el rastrillaje efectuado en las viviendas de la población para capturar a cualquier sospechoso con rostro indígena.

El periodista español Borja Loni y otro de nacionalidad argentina estuvieron, a pocas horas de lo ocurrido, en la Curva del diablo e Imacita e informaron a Alonso Gamarra, reportero del programa Enemigos íntimos, que la policía obstaculizaba sus indagaciones y desaparecían los cadáveres, que había cuerpos quemados y mutilados con heridas de bala a muerte y con balas para desfigurar sus rostro, que ellos tuvieron que apoyar a la población cuidando a los muertos ${ }^{25}$. También estuvieron presentes periodistas de la prensa extranjera, UNIVISIÓN, TVE, entre otros.

El país entero fue interpelado por los pueblos de la Amazonía. Gracias a la movilización generalizada de la población peruana y la solidaridad mundial, el gobierno del presidente García retrocedió, el primer ministro Yehude Simons declaró la derogatoria de la ley, no le quedó otra opción que reconocer la inconstitucionalidad del decreto legislativo 1090, la ley de la Selva, pues vulnera el convenio 169 de la OIT y la Declaración de las Naciones Unidas sobre los Derechos Indígenas. Sin embargo, hasta hoy no se sanciona a los responsables políticos. En marzo del 2011 el Tribunal Supremo Militar Policial condenó al general PNP ( $r$ ) Luis Muguruza Delgado y al general PNP ( $r$ ) Javier Uribe, pero ¿quiénes son los responsables políticos que gozan de impunidad? Recordemos que el 2009, gobernaba García y que Mercedes Cabanillas era ministra del Interior.

El juicio que se viene realizando en la Sala Penal Transitoria del Bagua, según referencias de la revista Ideele ${ }^{26}$, tiene muchas irregularidades, el juez Gonzalo Zabarburú suspende las sesiones cuando quiere, suele mofarse de los testigos indígenas o actúa de modo paternalista, en todo momento trata de ridiculizarlos; tampoco informa sobre las fechas de audiencia, evitando así que el proceso sea cubierto por los medios de comunicación. A pesar de existir algunas Resoluciones Administrativas, como la 257-2010 del Consejo Ejecutivo del Poder Judicial, que facilita la creación de una sala itinerante en Santa María de Nieva con el objeto de que los magistrados se acerquen a las comunidades comprendiendo las dificultades económicas de la población para trasladarse, el juez no se interesa por ellas.

No se aplica las normas internacionales de protección a los procesados indígenas, desconoce el convenio 169 de la OIT; el único documento que emplea es el código de procedimientos penales de 1940. El fiscal José Feliciano Novoa tampoco asume debidamente sus funciones, sus prioridades son otras, atiende su teléfono incluso

\footnotetext{
25 "Enemigos íntimos", Director: Beto Ortiz. https://www.youtube.com/watch?v=ZsOTREOwBwc\&ebc=ANyPxKr j3L9B7E-jcw9Hcul2jV4dUtBIcxcnUVIW5ss9EQfRerZSuEvv3TtBBy9CfeDFMuZuP7ql

26 Ideele Revista, № 244, Patricia Wiesse (directora), Gerardo Saravia (editor), Lima, 2014. http://www.revistaideele. com/ideele/content/la-tremenda-corte
} 
cuando los acusados están brindando su testimonio. Cuando interroga asume un tono despectivo. Por ejemplo, al preguntar "a un mestizo" manifestó : "Usted que es normal, responda...." Los indígenas y Apus que llegan con su tawa o su corona de plumas son maltratados. Toda intervención del abogado de IDL Juan José Quispe es objetada o interrumpida.

En la interacción cotidiana, el proceso irradia huellas Intersubjetivas teñidas de racismo, eurocentrismo y de dominación patriarcal; la interculturalidad es completamente desconocida para ellos. Los magistrados no se interesan por el artículo 89 que contiene un atisbo intercultural en la actual Constitución peruana, en tanto reconoce la autonomía organizativa, administrativa y económica de las comunidades nativas. El artículo 149 permite que las comunidades hagan uso de su derecho consuetudinario en su ámbito territorial. En el mismo código penal, el artículo 15 norma que "quien por su cultura o costumbres comete un hecho punible, sin poder comprender el carácter delictuoso de su acto, será eximido de responsabilidad".

Según la revista Ideele, existe un antecedente de aplicación intercultural que fue defendido en enero del 2013, en la misma Sala Penal Transitoria de Bagua. Salas Arenas, juez de la Corte Suprema, ratificó la sentencia emitida por esa sala, que absolvió a Zebelio Kayap, presidente de la Organización de Desarrollo de las Comunidades Fronterizas del Perú (Odecofrop), y a otros cuatro dirigentes acusados del delito de secuestro de funcionarios de la minera Afrodita, los comuneros retuvieron, por ocho días a varios trabajadores de la empresa el 15 de enero de 2009. Además, tanto Zabarburú y Novoa, el presidente y el fiscal respectivamente están denunciados por cohecho pasivo propio, entre otras denuncias. Es necesario precisar que el juicio se está conduciendo de modo irregular, sin garantías.

\section{Dialogando con los clásicos}

En acuerdo con Alimonda en la teoría clásica, en autores tales como Rosa Luxemburgo, Gramsci, Mariátegui, entre otros, es posible encontrar referentes en los cuales se entiende la experiencia colonial "como subordinación sistemática de sociedades periféricas a la lógica global de acumulación". Así, Alimonda encuentra que Luxemburgo da cuenta del dominio inglés en la India y Sudáfrica, del dominio francés en Argelia, territorios en los cuales usaron las prácticas tradicionales y de propiedad para imponer la propiedad privada y la dominación colonial. La recurrencia a los clásicos le permite rescatar del naufragio algunas de sus propuestas que por su dimensión crítica considera contienen signos vitales para reinterpretar desde nuestros interrogantes de hoy. En el caso de Marx, encuentra esta relación en la correspondencia que esta-

\section{2 / RELUSTA DE SOCOLOOGÍA 26}


bleció al final de sus días con Danielson. A través del género epistolar, se revela que Marx empezó a dudar del carácter progresivo de las fuerzas productivas. En lo que sigue dialogaré con el joven Marx, Luxemburgo y con intelectuales indoamericanos.

\title{
a) La relación entre el hombre y la naturaleza en Marx
}

Considero que Marx, en su edad temprana y al final de sus días, planteó algunas reflexiones en torno a la relación entre el hombre y la naturaleza que durante su madurez se eclipsaron. Al final de sus días, es revelador, a decir de Alimonda, que sus seguridades tambaleen, duda entre otros aspectos, en el "progreso histórico" a partir del desarrollo de las fuerzas productivas, pues estas pueden promover la destrucción de las comunidades locales y de la naturaleza.

En esta ocasión, por mi parte, me referiré al joven Marx, por cuanto en este período de su vida le interesa, entre otros aspectos, la relación: naturaleza, razón /cultura y diferencia sexual y la triada: naturaleza, capital y trabajo.

En Manuscritos: economía y filosofía, reflexiona en torno a la relación entre el hombre y la naturaleza. En primer lugar señala que el ser humano es un ser natural como una planta o un animal, un ser corpóreo limitado:

\begin{abstract}
El hombre es inmediatamente ser natural. Como ser natural, y como ser natural vivo, está, de una parte, dotado de fuerzas naturales, de fuerzas vitales, es un ser natural activo; estas fuerzas existen en él como talentos y capacidades, como impulsos; de otra parte, como ser natural, corpóreo, sensible, objetivo, es, como el animal y la planta un ser paciente, condicionado y limitado: esto es, los objetos de sus impulsos existen fuera de él, en cuanto objetos independientes de él, pero estos objetos son objetos de su necesidad ${ }^{27}$.
\end{abstract}

El segundo lugar, el ser humano es un ser activo con capacidades e impulsos. Lo reconoce como parte de la naturaleza en sus actos y su cuerpo. En la unidad de la dimensión inmaterial y material siendo un ser natural humano, tiene que afirmarse tanto en su ser natural como en su saber humano, es decir, naturaleza y cultura son fundamentales en el ser humano. Mas ¿qué es lo que separa al "ser natural humano" de su "saber humano"? La Naturaleza que radica en su ser corpóreo semejante al de una planta, le brinda la energía de la acción y los impulsos. Para Marx, esta energía que emana del cuerpo y la acción, va a ser condicionada y controlada cuando el ser humano se hace consciente de su existencia social y que sus actos hacen historia:"Ni objetiva ni subjetivamente existe la naturaleza inmediatamente ante el ser humano

27 Marx, Karl. Manuscritos: economía y filosofía. Madrid: Alianza Editorial, 1972, 194. 
en forma adecuada; y como todo lo natural tiene que nacer; también el hombre tiene su acto de nacimiento, la historia [... . La historia es la verdadera Historia Natural del hombre (a esto hay que volver) ${ }^{28}$.

Considero que estas reflexiones en su edad temprana quedan eclipsadas en Marx adulto por las prioridades de investigación, la acción política y de vida que opta en un medio intelectual con un predominio ilustrado y eurocéntrico. En los tramos finales de su vida, su experiencia vital, le revela la necesidad de dudar y de desaprender lo que consideraba certero.

\title{
La relación genérica y la diferencia sexual
}

En el tercer manuscrito, Marx precisa que la primera relación del hombre, genérico / especie universal con la naturaleza, es su vínculo con su diferencia sexual, la mujer:

\begin{abstract}
La relación inmediata natural y necesaria del hombre con el hombre, es la relación del hombre hacia la mujer. En esta relación natural de los géneros, la relación del hombre con la naturaleza es inmediatamente su relación con el hombre, del mismo modo que la relación con el hombre es inmediatamente su relación con la naturaleza, su propia determinación natural. En esta relación se evidencia, pues, de manera sensible, reducida a un hecho visible, en qué medida la esencia humana se ha convertido para el hombre en naturaleza o en qué medida la naturaleza se ha convertido en esencia humana del hombre. Con esta relación se puede juzgar el grado de cultura del hombre en su totalidad. Del carácter de esta relación se reduce la medida en que el hombre se ha convertido en ser genérico, el hombre y sea comprendido como tal; la relación del hombre con la mujer es la relación más natural del hombre con el hombre. En ella se muestra en qué medida la conducta natural del hombre se ha hecho humana o en qué medida su naturaleza humana se ha hecho para él naturaleza si ${ }^{29}$.
\end{abstract}

La condición humana y la cultura es construida desde la visión masculina, el hombre como genérico universal, pero es la mujer, su diferencia sexual, quien le recuerda su procedencia. La relación entre hombre y mujer indicará cuanto de naturaleza y cultura se expresa en el ser humano. Mujer y naturaleza están asociadas. Lo cual da cuenta de varios matices de significación en relación a la Naturaleza, una como un potencial de la que no es ajena ni la mujer ni el hombre, pero con un rol activo del hombre en la creación de saber/ cultura, lo que le otorga un plus. El control de la energía corporal y la existencia social implica poder.

28 Marx, Karl. Manuscritos: economía y filosofía. Madrid: Alianza Editorial, 1972, 196.

29 Marx, Karl. Manuscritos: economía y filosofía. Madrid: Alianza Editorial, 1972, 142.

\section{4/ REVISTA DE SOCIOLOGÍA 26}


En otro pasaje, la naturaleza es equivalente a tierra/propiedad, la dominación de la propiedad privada comienza con la propiedad territorial. En el feudalismo el señor tiene el dominio territorial y mantiene una relación más cercana con la tierra, esta aparece "como cuerpo inorgánico de su señor". En la época industrial, la naturaleza/ tierra se transforma en mercancía y por tanto en "extrañada para el hombre"

En la experiencia europea, la propiedad territorial transformada en mercancía supone que el monopolio/control reposado del señor feudal se torne en monopolio en movimiento, en una dura competencia, porque se cambia "el inactivo disfrute del sudor y de la sangre ajenos en el ajetreado comercio de ellos [...]. La división de la propiedad territorial corresponde, en efecto, al movimiento de la competencia en el dominio industrial" ${ }^{\prime 31}$. La Naturaleza alejada del hombre se convierte en mercancía.

La propiedad privada divorcia el trabajo, el capital y la tierra; separa el salario beneficio del capital y renta de la tierra. La economía política no proporciona ninguna explicación sobre el fundamento de la división del trabajo y capital, del capital y la tierra. Por eso, el joven Marx se propone comprender la conexión del sistema monetario con la propiedad privada, la codicia, la separación de trabajo, capital y tierra; comprender toda está enajenación atraviesa entender el proceso de intercambio y competencia. Entiende que el trabajador "no puede crear nada sin la naturaleza, sin el mundo exterior sensible. Esta es la batería en que su trabajo se realiza, en la que obra, en la que y con la que produce ${ }^{\prime \prime 32}$. La Naturaleza ofrece al trabajo medios de vida y medios para la subsistencia de sí mismo. La enajenación de la actividad humana práctica, es decir, la enajenación del trabajo, se daría en dos aspectos: la relación del trabajador con el producto del trabajo, este es un objeto ajeno; $y$, sin desvincularse de lo anterior, "la relación con el mundo exterior sensible, con los objetos naturales ${ }^{\prime \prime 33}$, donde la Naturaleza se le presenta como un mundo extraño hostil. El hombre como el animal, "vive de la naturaleza inorgánica, y cuanto más universal es el hombre que el animal, tanto más universal es el ámbito de la naturaleza inorgánica de la que vive ${ }^{34}$. Las plantas, los animales, las piedras, el aire, la luz, etc., constituyen teóricamente una parte de la conciencia humana y de la existencia, en parte son objetos de la ciencia natural y, por otra, son objetos del arte, por su riqueza / naturaleza inorgánica espiritual (medios de subsistencia espiritual). Constituyen la unidad material y espiritual.

La universalidad del hombre sería posible porque hace de la Naturaleza toda su cuerpo inorgánico, en tanto constituye la fuente de medios de subsistencia inmediato, y por ser la materia, el objeto y el instrumento de su actividad vital. Siendo

\footnotetext{
Marx, Karl. Manuscritos: economía y filosofía. Madrid: Alianza Editorial, 1972, 98. Marx, Karl. Manuscritos: economía y filosofía. Madrid: Alianza Editorial, 1972, 100. Marx, Karl. Manuscritos: economía y filosofía. Madrid: Alianza Editorial, 1972, 107. Marx, Karl. Manuscritos: economía y filosofía. Madrid: Alianza Editorial, 1972, 110. Marx, Karl. Manuscritos: economía y filosofía. Madrid: Alianza Editorial, 1972, 110.
} 
"la naturaleza el cuerpo inorgánico del hombre", por cuánto le brinda privilegiado sustento y hace posible la relaciones sociales, concibe que "la naturaleza, en cuanto ella misma, no es cuerpo humano". Al mismo tiempo, aclara que cuando señala que el hombre "vive de la naturaleza quiere decir que la naturaleza es su cuerpo, con el cual ha de mantenerse el proceso continuo para no morir. Que la vida física y espiritual del hombre está ligada con la naturaleza no tiene otro sentido que el de que la naturaleza está ligada consigo misma, pues el hombre es una parte de la naturaleza"35. Como sabemos, es el trabajo enajenado, en primer lugar, lo que "convierte a la naturaleza en algo ajeno al hombre" $y$, en segundo, "lo hace ajeno de sí mismo, de su propia función activa, de su actividad vital, también hace del género algo ajeno al hombre; hace que para él la vida genérica se convierta en un medio de la vida individual" ${ }^{\prime \prime 3}$. Hace extrañas entre sí la vida genérica (comunitaria/natural) y la vida individual.

Si bien el joven Marx, nos permite comprender la relación entre el eurocentrismo y el proceso de enajenación al que nos somete la propiedad privada, por cuanto tierra y fuerza de trabajo constituyen la fuente inmediata de acumulación que brinda al capital una gran fuerza expansiva, no logra ver la relación y expansión colonial que junto a la clasificación racializada, incrementa sostenidamente la acumulación global por apropiación de las riquezas naturales y de la fuerza de trabajo de los territorios y cuerpos colonizados. Finalmente, Marx adulto abandona la triada: fuerza de trabajo, tierra y capital por la relación capital/ trabajo y es lo que ha quedado en la teoría marxista.

La dinámica cambiante del ser y el acontecer nos permite entender, la provisionalidad del saber, ahí radica su complejidad; por eso, acercarnos a la teoría clásica con una mirada abierta, crítica, despatriarcal y descolonial, supone partir de esa dinámica, comprender la relación entre poder, espacio y tiempo.

\section{b) La acumulación capitalista y los procesos coloniales}

Para Rosa Luxemburgo la acumulación de capital no se basa exclusivamente en relaciones capitalistas de producción:

(...) no hay ninguna razón por virtud de la cual todos los medios de producción y consumo necesarios hayan de ser elaborados exclusivamente en producción capitalista. En la primera mitad del siglo XIX, la plusvalía salía del proceso de producción, en su mayor parte en forma de telas de algodón. Pero los elementos materiales de su capitalización: algodón procedente de los estados esclavistas de la Unión Americana o cereales (medios de subsistencia para los obreros

35 Marx, Karl. Manuscritos: economía y filosofía. Madrid: Alianza Editorial, 1972, 111.

36 Marx, Karl. Manuscritos: economía y filosofía. Madrid: Alianza Editorial, 1972, 111.

\section{6/ REVISTA DE SOCIOLOGÍA 26}


ingleses) procedentes de los campos de la Rusia con servidumbre de la gleba, representaban, sin duda, plusproducto, mas, de ningún modo, plusvalía capitalista. Hasta qué punto la acumulación capitalista depende de estos medios de producción, no producidos por el capitalismo, lo prueba la crisis algodonera inglesa, causada por el abandono de las plantaciones de algodón sobrevenido durante la Guerra de Secesión americana; o la crisis de la lencería europea causada por la interrupción de la importación de lino ruso Durante la guerra de Oriente. Por lo demás, basta recordar el papel que en Europa desempeña la importación de cereales no producidos en forma capitalista para el sustento de la masa de obreros industriales (es decir, como elemento del capital variable) para comprender hasta qué punto la acumulación del capital, en sus elementos materiales, se haya ligado, de hecho, a esferas no capitalistas $^{37}$.

Luxemburgo, logra desentrañar dos cuestiones centrales: que la acumulación capitalista se expande con los procesos coloniales a partir del trabajo esclavo y servil, y de las riquezas naturales en las colonias y que por eso la acumulación capitalista no se da exclusivamente mediante el trabajo asalariado.

\section{c) Dialogando con intelectuales indoamericanos}

En torno a esto, desde América Latina, Edgardo Lander precisa acertadamente, que cuando se abstrae a la naturaleza (espacio / territorio), "el desarrollo histórico de la sociedad moderna y del capitalismo aparecen como un proceso interno, auto generado de la sociedad europea, que posteriormente se expande hacia regiones "atrasadas". En esta construcción eurocéntrica, desaparece del campo de visión el colonialismo como dimensión constitutiva de estas experiencias históricas"38.

Fernando Coronil, por su parte, propone reemplazar la relación capital/trabajo que predomina en la teoría marxista por capital / trabajo/ naturaleza, lo cual nos ayudará a comprender mejor el proceso y a tener una visión más clara del capitalismo y la modernidad: "Incluir la tierra en la dialéctica capital/trabajo/ naturaleza nos permite reconocer que el proceso de la creación de riqueza implica un intercambio transformativo entre los seres humanos y el mundo natural del cual forma parte"39. Agrega que en lugar de "una narrativa de la historia construida en términos de una posición entre un Europa moderna que ha triunfado por su propio esfuerzo y

37 Luxemburgo, Rosa; La acumulación del capital. Edicions Internacionals, Sedov / Germinal.1912, 172-173.

38 Lander, Edgardo; "Ciencias sociales: saberes coloniales y eurocéntricos”, La colonialidad del saber: eurocentrismo y ciencias sociales. Perspectivas latinoamericanas. Lander (comp.), Buenos Aires: CLACSO, 2000, 359.

39 Coronil, Fernando; "Naturaleza del post colonialismo: del eurocentrismo al globo centrismo". La colonialidad del saber: eurocentrismo y ciencias sociales. Perspectivas latinoamericanas. Lander (comp.), Buenos Aires, CLACSO, 2000, 91. 
una periferia unida en medio de su atrasada cultura, este cambio de perspectiva nos permite apreciar más cabalmente el papel de la naturaleza (neo) colonial y del trabajo en la mutua formación transcultural de las modernidades metropolitanas y subalternas" ${ }^{\prime 4}$.

El capitalismo surge y se fortalece mediante la relación colonial, y lo que Aníbal Quijano ha denominado la colonialidad del poder a partir de la idea de raza y el eurocentrismo emergente como patrón de poder en 1492. El capitalismo y el progreso catalogados como invención europea no existió ni existe sin la colonización de los cuerpos considerados natural y supuestamente inferiores en tanto "raza": los "indios", "negros" $y$ "mestizos"; $y$, agregamos; sin la colonización y apropiación del cuerpo y el trabajo de las mujeres "indias", "negras" y"mestizas"; esto es, sin la economía del cuidado y el trabajo doméstico que abarcaba y abarca aún los procesos de reproducción de la vida y las estructuras productivas, sin este trabajo no sería posible el trabajo productivo ni la acumulación capitalista.

La cusqueña Clorinda Matto, a fines del siglo XIX, sostuvo que fueron dos géneros de minas los que alimentaron material e intelectualmente a los europeos: los metales preciosos y las minas hablantes de estos territorios. Tiempo después, Coronil, siguiendo a Mintz, agregará que las plantaciones de azúcar de las Américas con trabajo de esclavos africanos fueron las fábricas que precedieron a las del Liverpool. La "acumulación primitiva colonial" lejos de ser una precondición del desarrollo capitalista, ha sido un elemento indispensable de su dinámica interna. Del mismo modo, hoy sabemos que el trabajo asalariado en Europa no es la condición esencial del capitalismo, sino una modalidad histórica condicionada por el trabajo no libre, es decir servil y esclavo en las colonias. Aquí se conjugan los procesos coloniales de acumulación con la clasificación racializada de la población.

\section{¿Qué relación tiene esto con los acontecimientos ocurridos en Bagua?}

Los gobiernos de América Latina, incluido los progresistas, suelen sostener que el desarrollo a partir de la explotación extractivista y agroindustrial conduce a un progreso intensivo y lo defienden aún a costa de la vida de la población y la destrucción de la Naturaleza. Los dolorosos hechos ocurridos en Bagua y en otros territorios de América Latina son una muestra de ello. Poco importa el cambio climático que afecta la vida misma del planeta, es urgente recordar que en los dos

40 Coronil, Fernando; "Naturaleza del post colonialismo: del eurocentrismo al globo centrismo". La colonialidad del saber: eurocentrismo y ciencias sociales. Perspectivas latinoamericanas. Lander (comp.), Buenos Aires, CLACSO, 2000, 92.

\section{8/ RELUSTA De SOCOLOOGÍA 26}


últimos años se ha incrementado la emisión de CO2. La Agencia Internacional de Energía señaló el 2013 que en el mundo no se alcanzará el objetivo acordado por los gobiernos de limitar a largo plazo la elevación de la temperatura media mundial a 2 Grados Celsius $\left({ }^{\circ} \mathrm{C}\right) .{ }^{41}$

Hoy en día, el estado peruano y los estados latinoamericanos, parecen expresar que pueden reconocer la diversidad cultural y hasta denominarse pluricultural y plurinacional, pero sin tocar la economía, en su visión cultura y economía son dimensiones divorciadas como si la economía no fuese también una invención cultural que junto a la ciencia moderna están contribuyendo a destruir la Naturaleza. La ciencia económica y sus perspectivas de desarrollo se presentan como un conocimiento objetivo y universal, lo cual pone en evidencia discursos neopositivistas en el saber.

El paradigma reduccionista de la ciencia parte de la separación jerárquica entre mente y cuerpo, naturaleza y cultura. Situación que se agrava con los procesos de recolonización de los territorios de nuestra América. Como sabemos y como bien lo indican Maria Mies y Vandana Shiva, las fuerzas liberadoras que emergían del paradigma científico occidental no fueron para el conjunto de los seres humanos, sino que significó la subyugación/ colonización de la naturaleza y las mujeres en el propio territorio europeo ${ }^{42}$. En los pueblos no europeos, esta situación se agravó, agrego, por las condiciones de trabajo, sujetas a la clasificación racializada de la población y el eurocentrismo. Shiva y Mies desde distintos lugares de enunciación coinciden con Dussel y Quijano, al precisar que la modernidad y la ciencia moderna nació con y gracias a América.

La tradición epistémica moderna, el patriarcalismo y la colonialidad del poder niegan la existencia de otras formas de saber y deshecha la capacidad de regeneración y renovación creativa de la naturaleza. La naturaleza, en tanto supuesto objeto inerte, desde esta visión, expresaría como nos lo hace notar Shiva, el no valor y el conocimiento a través de las políticas extractivistas, agregamos, el valor, de este modo se coloniza y controla lo que es gratuito y capaz de autogeneración.

Hoy en día, para resolver las crisis provocadas por ellos mismos, los estados centrales y las corporaciones están diseñando estrategias de recolonización de los territorios de nuestra América, lo ocurrido en Bagua forma parte de este proceso. Con todo, los pueblos de América Latina, hoy no solo resisten como lo han venido haciendo durante más de 500 años, sino que se afirman organizándose en la defensa de sus territorios y de la vida.

41 "Agencia Internacional de Energía (AIE): las energías renovables (eólica, fotovoltaica y termosolar) serán la segunda fuente en 2016", en Reve, 27 junio, 2013. http://www.evwind.com/2013/06/27/agenciainternacional-de-energia-aie-las-energias-renovables-eolica-fotovoltaica-y-termosolar-seran-la-segundafuente-en-2016/

42 Mies, María; Shiva, Vandana; Ecofeminismo. Teoría, crítica y perspectivas. Barcelona, Icaria, 1997 [1993], p. 39. 


\section{Coda}

El 7 de junio de 1989, se creó el convenio 169 de la Organización Internacional del Trabajo, ratificado por el Perú en 1994 con la Ley № 26253. El convenio establece garantizar la autonomía interna de los pueblos y nacionalidades indígenas, el derecho a ser consultado y a participar en la toma de decisiones. A pesar que el Perú ratificó la Ley, los pueblos y nacionalidades indígenas no han merecido una debida y respetuosa consulta. La ley 26505 , que parecía promover y cumplir con la consulta previa, ha venido siendo recortada. Mediante las facultades extraordinarias que el Congreso de la República otorgó al expresidente Alan García, se emitieron leyes que afectaron aún más el territorio y a las comunidades que lo habitan, esto desencadenó la movilización comunal indígena que constituye un punto de inflexión con el modelo de desarrollo extractivista impuesto en el Perú.

Lo acontecido forma parte de las estrategias de recolonización de los territorios de nuestra América, en particular de la Amazonía, constituye la tendencia de apoyo del "Estado nación" y de la burocracia que lo sostiene, a la reconcentración del control y explotación de la Naturaleza por el capitalismo colonial/global, la dominación patriarcal y patrimonial. Las comunidades indígenas que participaron dan cuenta que la organización, las relaciones de autoridad y tomas de decisión en las comunidades no están centralizadas en los dirigentes si no en sus representados. Ellos consultan y obedecen a sus representados porque las decisiones son tomadas por la comunidad en pleno. De este modo, las comunidades afectadas dan lecciones de una democracia de mayor intensidad; lo que está en juego son epistemes/cosmovisiones e intereses distintos en relación a la economía, la cultura, la naturaleza, la jurisprudencia, las maneras de conocer y producir conocimiento y la concepción de la vida en general.

La población de Bagua entrevistada se expresa mediante un yo plural que se autodefine como una comunidad pacífica:"nosotros no somos terroristas","nosotros somos pacíficos"; evidencia y devela la colonialidad del poder a partir de la injusta, racista y autoritaria"integración" de la"nación peruana", porque"integra" destruyendo. En ese sentido, el conflicto da cuenta de la resistencia indígena y de la población que se organizó comunal y solidariamente, y de las contradicciones entre la existencia social comunitaria y el "estado nación" que representa a las corporaciones.

El territorio, desde la visión de las comunidades indígenas de la Amazonía, no se refiere exclusivamente a la geografía, comprende la biodiversidad y sus prácticas culturales, sus instituciones propias, lenguas ancestrales $y$, sobre todo, un episteme /cosmovisión subalternizado, pues todo lo existente es un ser vital semejante al ser humano. Por eso, en concordancia con Prada, no existe plenamente la idea de

\section{0/ RELUSTA DE SOCOLOOGÍA 26}


propiedad, el territorio no puede ser solo de una persona o de un grupo de personas; por el contrario, la comunidad forma parte del territorio. Todo lo existente se comparte con todos los seres no humanos con los que se convive. Para las comunidades de la Amazonía, la vida comunal supone acción individual y colectiva en estrecha relación con la Naturaleza. Las actividades suelen estar acompañadas de fiesta y mística en la que ella participa activamente, en un medio en el que si bien la idea de acumulación y propiedad no está plenamente establecida, puja por introducirse desde las instituciones hegemónicas del "estado nación", los medios de comunicación y el mercado.

El joven Marx nos permite comprender tres aspectos: 1. que el trabajo enajenado, "convierte a la naturaleza en algo ajeno al hombre", 2. que "lo hace ajeno de sí mismo", 3. hace extrañas entre sí la vida genérica (comunitaria/natural) y la vida individual, y agrego uno más, que este proceso de enajenación al que nos somete la propiedad privada, hace "olvidar" al saber hegemónico, sobretodo en las ciencias sociales, que la relación entre Naturaleza y fuerza de trabajo constituyen la fuente de acumulación que brinda al capital una gran fuerza expansiva, pero ni el joven Marx ni el saber eurocéntrico y patriarcal logran develar la relación y expansión colonial percibida, desde otros lugares de enunciación, por la población indígena de la Amazonía, Rosa Luxemburgo, Vandana Shiva, María Mies, José Carlos Maríátegui, Aníbal Quijano, entre otros, que junto a la clasificación racializada y la diferencia sexual incrementa sostenidamente la acumulación global por apropiación de las riquezas naturales / bienes comunes y de la fuerza de trabajo de los territorios y cuerpos colonizados. Marx adulto abandonó la triada: fuerza de trabajo, tierra/Naturaleza y capital por la relación capital/ trabajo, y esto es lo que ha quedado en la teoría marxista. En las perspectivas desarrollistas extractivistas de la cosmovisión del patrón moderno colonial global que niega la existencia de otras formas de saber, la Naturaleza es un objeto inerte que se requiere controlar y explotar sin medida aún a costa de la vida del planeta. Por eso, es imprescindible recordar que la organización comunitaria de los pueblos de la Amazonía en defensa de sus territorios y de la vida tiene como principio vital alternativo:"bonito tienes que pensar, bonito tienes que actuar, bonito tienes que hacer"43, principio que todavía suele acompañarlos en la cotidianidad de la existencia individual y colectiva.

Agosto, 2016

43 Hugo Jamioy Juagibioy, Binÿbe oboyejuayëng/Danzantes del viento. Véase: Poéticas afro interamericanas: episteme, cuerpo y territorio. Carolina Ortiz Fernández, Lima, Fondo Editorial Facultad de Ciencias Sociales de la UNMSM, 2014. 


\section{Referencias bibliográficas}

Agencia Internacional de Energía (AIE): "Las energías renovables (eólica, fotovoltaica y termosolar) serán la segunda fuente en 2016", en Reve, 27 junio, 2013. Amazonía del Perú. Recuperado: http://www.evwind.com/2013/06/27/agencia-internacional-de-energia-aielas-energias-renovables-eolica-fotovoltaica-y-termosolar-seran-la-segunda-fuente-en-2016/

AMAT Y LEÓN, Carlos, El Perú nuestro de cada día. Nueve ensayos para discutir y decidir. Lima, Universidad del Pacífico, 2006.

AYALA, José Luis; "Cosmovisión ancestral y contemporánea”, América Latina en debate, II Foro Internacional ALAS- 2011, Lima, URP, 2012, 499

ALIMONDA, Héctor; "Provocaciones sobre el tema“"Extractivismo y Desarrollo'"', en Polis. Revista Latinoamericana, № 41, 2015. http://polis.revues.org/10925

DE SEPÚlVEDA, Ginés; Tratado de las justas causas de la guerra contra los indios. México, FCE., 1996.

CORONIL, Fernando;"Naturaleza del post colonialismo: del eurocentrismo al globo centrismo". La colonialidad del saber: eurocentrismo y ciencias sociales. Perspectivas latinoamericanas. Lander (comp.), Buenos Aires, CLACSO,2000.

Enlace Nacional; Declaraciones de la ministra Rosario Fernández a Enlace Nacional, el domingo 07 de junio de 2009, a 11:45 a.m. http://enlacenacional.com/2009/06/05/enfrentamientoentre-policias-y-nativos-en-bagua-deja-tragico-saldo/

EsCOBAR, Arturo; “El Lugar de la naturaleza y la naturaleza del lugar: ¿globalización o post desarrollo?". La colonialidad del saber: eurocentrismo y ciencias sociales. Perspectivas latinoamericanas. Lander (comp.), Buenos Aires, CLACSO,2000.

Federación Regional de Mujeres Ashaninkas, Nomatsiguengas y Kakintes de la Selva Central (FREMANK), "Pronunciamiento", 9 de junio de 2009. http://www.justiciaviva.org.pe/ nuevos/2009/junio/11/7.pdf

GARCíA PÉREZ,Alan; “El síndrome del perro del hortelano", en: Diario El Comercio. Lima, 28 de octubre de 2007.

GARCÍA PÉREZ, Alan; Declaración a UNIVISION y TVE el 9 de junio de 2009. https://www.youtube. com/watch?v=rlj6XBa7pAE\&ebc=ANyPxKrj3L9B7E-jcw9Hcul2jV4dUtBlcxcnUVIW5ss9EQfRerZSuEvv3TtBBy9CfeDFMuZuP7ql

HildebRANDT, César; Entrevista a Mercedes Araos, en: El perro del hortelano https://www. youtube.com/watch?v=t6c6nqkyyLI , subido el 15 de junio del 2009.

HILDEBRANDT, César; Entrevista a Champion Nomingo Cesen, en: El perro del hortelano 07 de junio del 2009

HolLAND-KunZ, Bárbara; Ecofeminismos, Madrid, Cátedra, 1996.

INEI, Censos nacionales, Lima, 1993.

LANDER, Edgardo; "Ciencias sociales: saberes coloniales y eurocéntricos”, La colonialidad del

\section{2/ REEUSTA DE SOCOLOOGíA 26}


saber: eurocentrismo y ciencias sociales. Perspectivas latinoamericanas. Lander (comp.), Buenos Aires, CLACSO,2000.

LUXEMBURGO, Rosa; La acumulación del capital, Edicions Internacionals, Sedov/Germinal, 1912. Recuperado: http://grupgerminal.org/?q=system/files/LA+ACUMULACIÓN+DEL+CAPITAL. pdf

MARX, Karl; Manuscritos economía y filosofía, Madrid, Alianza Editorial 1972.

MIES, Maria; SHIVA, Vendana; Ecofeminismo. Teoría, crítica y perspectivas. Barcelona, Icaria, 1997[1993], p. 39.

MINISTERIO DE AGRICULTURA; "Ley de inversión privada en el desarrollo de las actividades económicas en las tierras del territorio nacional y de las comunidades campesinas y nativas".( ley de tierras) http://www.cepes.org.pe/legisla/ley26505.htm

MINAM; "Ley general de ambiente 28611", http://www.minam.gob.pe/wp-content/uploads/2013/06/ley-general-del-ambiente.pdf

OIT. Oficina Regional para América Latina y el Caribe. “Convenio N 169 sobre pueblos indígenas y tribales en países independientes". 2a.ed. Lima, OIT, Oficina Regional paraAmérica Latina y el Caribe, 2007.106p. http://www.oit.org.pe/WDMS/bib/publ/libros/convenio_169_07. pdf

ORTIZ, Beto; Director, “Enemigos íntimos", 9 de junio de 2009. Recuperado: https://www.youtube. com/watch?v=ZsOTREOwBwc\&ebc=ANyPxKrj3L9B7E-jcw9Hcul2jV4dUtBlcxcnUVIW5ss9EQfRerZSuEvv3TtBBy9CfeDFMuZuP7ql

ORTIZ, Beto; Director, “Enemigos íntimos”, "Madre indígena reclama a Alan García”. Recuperado, 10 junio 2009. https://www.youtube.com/watch?v=D--_jZ6KHpw

ORTIZ FERNÁNDEZ, Carolina; Poéticas afroindoamericanas. Episteme, cuerpo y territorio", Lima, Pakarina ediciones/UNMSM, 2014.

ORTIZ FERNÁNDEZ, Carolina; "Bagua en el corazón”, Revista de Sociología, Lima, UNMSM, 2014.

Ortiz FernÁndez, Carolina; Procesos de descolonización del imaginario y del conocimiento en América Latina, Lima, Fondo Editorial la Facultad de Ciencias Sociales, UNMSM, 2004.

PALACIOS, Rosa María; Entrevista a Mercedes Cabanillas, Prensa Libre, 5/9/2009. https://www. youtube.com/watch?v=upLUGHNB6WI

PRAdA AlcorezA, Raúl; "Territorios indígenas y descolonización". En Linea de fuego, septiembre 1, Bolivia, 2015. http://lalineadefuego.info/2015/09/01/territorios-indigenas-y-descolonizacion-por-raul-prada-alcoreza/

QUIJANO, Aníbal; "<< Bien vivir >> : entre el <<desarrollo >> y la descolonialidad del poder", Descolonialidad y bien vivir. Un nuevo debate en América Latina, Lima, URP, 2014.

QUIJANO, Aníbal “Colonialidad y modernidad/racionalidad", en: Revista del Instituto Indigenista Peruano, Vol. 13, (1991) No. 29, Lima, pp. 11-20.

QUIJANO, Aníbal "Colonialidad, poder, cultura y conocimiento en América Latina”, en: Walter Mignolo (comp.), Capitalismo y geopolítica del conocimiento. El eurocentrismo y la 
filosofía de la liberación en el debate intelectual contemporáneo, 2001, Buenos Aires, El Signo, pp. 117-131.

SHADY, Ruth; La Arqueología de la cuenca inferior del Utcubamba, tesis para optar el grado de doctora en el Programa Académico de Antropología y Arqueología, Facultad de Ciencias Sociales,UNMSM, Lima, 1973.

TORERO, Alfredo; "La hoya de Jaén en el siglo XVI", en Revista Andina № 22, 1993. http:// enlacenacional.com/2009/06/05/enfrentamiento-entre-policias-y-nativos-en-baguadeja-tragico-saldo/

Universidad Nacional Agraria La Molina, Boletín Informativo Caoba º3 - 2008, Eecuperado: http://www.lamolina.edu.pe/proyectocaoba/Boletin\%203.pdf

WEBER, Max; Economía y sociedad, España, FCE, 1993.

WIESSE, Patricia; directora, "La tremenda corte", Revista Ideele, № 244, Gerardo Saravia (editor), Lima, 2014. Recuperado: http://www.revistaideele.com/ideele/content/la-tremenda-corte 